\title{
PTR-QMS versus PTR-TOF comparison in a region with oil and natural gas extraction industry in the Uintah Basin in 2013
}

\author{
C. Warneke ${ }^{1,2}$, P. Veres ${ }^{1,2}$, S. M. Murphy ${ }^{3}$, J. Soltis ${ }^{3}$, R. A. Field ${ }^{3}$, M. G. Graus ${ }^{1,2,{ }^{*}}$, A. Koss ${ }^{1,2}$, S.-M. Li ${ }^{4}$, R. Li ${ }^{1,2}$, \\ B. Yuan ${ }^{1,2}$, J. M. Roberts ${ }^{2}$, and J. A. de Gouw ${ }^{1,2}$ \\ ${ }^{1}$ Cooperative Institute for Research in Environmental Sciences, Univ. of Colorado, Boulder, CO, USA \\ ${ }^{2}$ NOAA Earth System Research Laboratory, Chemical Sciences Division, Boulder, CO, USA \\ ${ }^{3}$ Department of Atmospheric Science, University of Wyoming, Laramie, WY, USA \\ ${ }^{4}$ Air Quality Process Research Division, Environment Canada, Toronto, ON, Canada \\ *now at: Institute of Meteorology and Geophysics, Innsbruck University, Innsbruck, Austria
}

Correspondence to: C. Warneke (carsten.warneke@noaa.gov)

Received: 28 May 2014 - Published in Atmos. Meas. Tech. Discuss.: 3 July 2014

Revised: 4 December 2014 - Accepted: 9 December 2014 - Published: 26 January 2015

\begin{abstract}
Here we compare volatile organic compound (VOC) measurements using a standard proton-transferreaction quadrupole mass spectrometer (PTR-QMS) with a new proton-transfer-reaction time of flight mass spectrometer (PTR-TOF) during the Uintah Basin Winter Ozone Study 2013 (UBWOS2013) field experiment in an oil and gas field in the Uintah Basin, Utah. The PTR-QMS uses a quadrupole, which is a mass filter that lets one mass to charge ratio pass at a time, whereas the PTR-TOF uses a time of flight mass spectrometer, which takes full mass spectra with typical $0.1 \mathrm{~s}-1 \mathrm{~min}$ integrated acquisition times. The sensitivity of the PTR-QMS in units of counts per ppbv (parts per billion by volume) is about a factor of 10-35 times larger than the PTR-TOF, when only one VOC is measured. The sensitivity of the PTR-TOF is mass dependent because of the mass discrimination caused by the sampling duty cycle in the orthogonal-acceleration region of the TOF. For example, the PTR-QMS on mass 33 (methanol) is 35 times more sensitive than the PTR-TOF and for masses above $120 \mathrm{amu}$ less than 10 times more. If more than 10-35 compounds are measured with PTR-QMS, the sampling time per ion decreases and the PTR-TOF has higher signals per unit measuring time for most masses. For UBWOS2013 the PTR-QMS measured 34 masses in $37 \mathrm{~s}$ and on that timescale the PTRTOF is more sensitive for all masses. The high mass resolution of the TOF allows for the measurements of compounds that cannot be separately detected with the PTR-QMS, such as oxidation products from alkanes and cycloalkanes emit-
\end{abstract}

ted by oil and gas extraction. PTR-TOF masses do not have to be preselected, allowing for identification of unanticipated compounds. The measured mixing ratios of the two instruments agreed very well $\left(R^{2} \geq 0.92\right.$ and within $\left.20 \%\right)$ for all compounds and masses monitored with the PTR-QMS.

\section{Introduction}

The measurements of volatile organic compounds (VOCs) with proton-transfer-reaction quadrupole mass spectrometry (PTR-QMS) have become a standard technique in atmospheric measurements on various platforms such as ground sites, ships and aircraft, because of its high time resolution and sensitivity. The instrument has been described and characterized in great detail over the last several years (Blake et al., 2009; de Gouw and Warneke, 2007; Hansel et al., 1995, 1999; Lindinger et al., 1998a, b; Warneke et al., 2001, 2003, 2011b) and many successful intercomparisons with other techniques such as gas chromatography mass spectrometry (GC-MS) have demonstrated the sensitivity and the selectivity of PTR-QMS (de Gouw et al., 2003; de Gouw and Warneke, 2007; Haase et al., 2012; Wisthaler et al., 2008). PTR-QMS is a chemical ionization mass spectrometry technique that detects VOCs using proton transfer reactions with $\mathrm{H}_{3} \mathrm{O}^{+}$, but has the drawback that only the nominal unitresolution mass of one VOC at a time can be determined. To improve on the selectivity three approaches have been fre- 
quently investigated: (1) instead of $\mathrm{H}_{3} \mathrm{O}^{+}$different reagent ions (Sulzer et al., 2012) have been used such as $\mathrm{NO}^{+}$, $\mathrm{O}_{2}^{+}, \mathrm{NH}_{4}^{+}$and $\mathrm{Kr}^{+}$, (2) gas chromatographic preseparation of VOCs prior to PTR-QMS detection (Karl et al., 2001; Warneke et al., 2003) and (3) isomers are distinguished by fragmentation patterns generated with collision-induced dissociation (CID) (Müller et al., 2009; Warneke et al., 2004). In addition, other mass spectrometers have been used in place of the quadrupole such as ion traps (Mielke et al., 2008; Prazeller et al., 2003; Warneke et al., 2005a, b) and time of flight (TOF) mass spectrometers (Blake et al., 2004; Tanimoto et al., 2007).

The PTR-TOF instrument (Graus et al., 2010; Jordan et al., 2009; Müller et al., 2010) was recently developed by the University of Innsbruck and Ionicon Analytik and is commercially available. It is aimed to improve on the time response and on the selectivity of PTR-QMS by using a high-resolution TOF mass spectrometer from Tofwerk AG, which has the capability of recording mass spectra at a very high frequency $(>10 \mathrm{~Hz})$ and with a high mass resolution ( $>4000 \mathrm{~m} / \Delta \mathrm{m}$ ). This mass resolution is often sufficient to distinguish between isobaric compounds.

Here we compare a commercial PTR-TOF with a standard PTR-QMS, both of which were operated side-by-side during a measurement campaign (UBWOS2013 - Uintah Basin Winter Ozone Study 2013) in an area of oil and natural gas exploration in the Uintah Basin, Utah. We evaluate the stability, sensitivity and the detection limits of both instruments and determine which instrument is more sensitive in a given measurement mode. We also describe the advantages and the additional science that can be done with PTR-TOF using the data from the UBWOS2013 campaign.

\section{Experimental}

\subsection{UBWOS2013 field campaign}

The UBWOS2013 was conducted in January and February 2013 in the Uintah Basin, Utah. This area has a very low population density, but about 10000 active oil and natural gas wells are located within the basin. A map of the Uintah Basin study area with the oil and natural gas wells is shown in Fig. 1. This intense oil and natural gas extraction operation results in emissions of greenhouse gases, VOCs and nitrogen oxides $\left(\mathrm{NO}_{\mathrm{x}}\right)$ (Gilman et al., 2013; Helmig et al., 2014; Howarth et al., 2011; Karion et al., 2013; Katzenstein et al., 2003; Kemball-Cook et al., 2010; Litovitz et al., 2013; Petron et al., 2012). The UBWOS2013 campaign was designed to investigate the unusual wintertime ozone production that was observed in basins with oil and natural gas exploration during strong inversions and snow-covered surfaces (Edwards et al., 2013; Helmig et al., 2014; Schnell et al., 2009).

Measurements were done at the heavily instrumented Horse Pool ground site, which is also shown in Fig. 1. Dur-

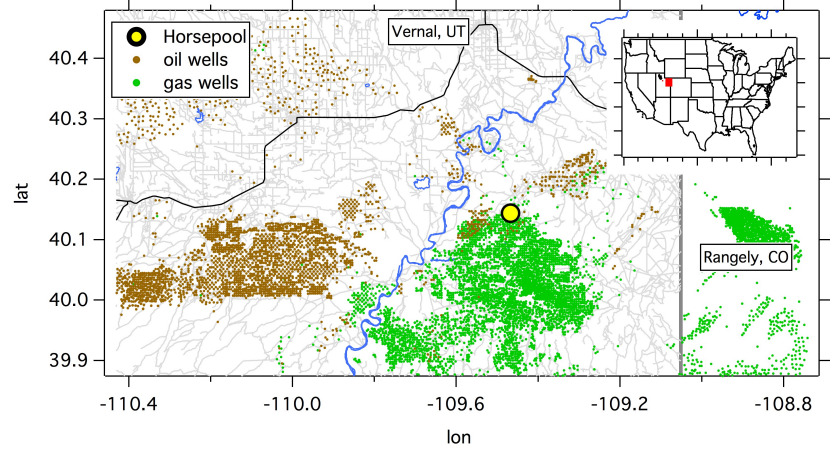

Figure 1. Map of the study area with the Horse Pool ground site in the Uintah Basin, Utah.

ing UBWOS2013, cold temperatures, snow on the ground and strong temperature inversions provided ideal conditions for wintertime ozone production and indeed ozone mixing ratios at Horse Pool exceeded 120 ppbv (parts per billion by volume) on several days. Emissions from oil and natural gas exploration in the Uintah Basin are mainly alkanes, cycloalkanes and aromatics related to the natural gas (Warneke et al., 2014), but active photochemistry produces, besides ozone, many different oxygenated VOCs (oxyVOCs). The Uintah Basin presents a unique VOC mix that is an excellent test case for demonstrating the additional capabilities of PTR-TOF, because many of the photochemically produced oxyVOCs are difficult to identify with standard PTR-QMS.

\subsection{PTR-QMS and PTR-TOF instruments}

PTR-QMS and PTR-TOF both use similar reaction chambers in which proton transfer reactions of $\mathrm{H}_{3} \mathrm{O}^{+}$are used to ionize the VOCs of interest (Lindinger et al., 1998a). The main difference between the two instruments is the mass spectrometer, which is a quadrupole QMS420 from Pfeiffer Vacuum for the PTR-QMS and an orthogonal acceleration reflectron TOF-MS from Tofwerk AG for the PTR-TOF. Both instruments were housed in the same instrument trailer and sampled from a common inlet manifold that pulled $20 \mathrm{~L} \mathrm{~min}^{-1}$ through a $15 \mathrm{~m}$ long Teflon inlet.

The PTR-QMS (owned by the Chemical Sciences Division of NOAA) has been used extensively in various field and laboratory experiments including several ground-based, ship and airborne deployments over the past 15 years and has been characterized and described in much detail previously (de Gouw and Warneke, 2007). During this measurement campaign standard operating conditions of $2.4 \mathrm{mbar}$ and $720 \mathrm{~V}$ resulting in an electric field/number density $(E / N)$ of about $125 \mathrm{Td}$ (Townsend) in the drift tube were used. Instrument backgrounds were determined every $3 \mathrm{~h}$ for about $3.5 \mathrm{~min}$ using a catalytic converter. Calibrations were done about every other day using three different calibration standards containing VOC mixtures in nitrogen. Using the mobile organic 
carbon calibration system (MOCCS; Veres et al., 2010), formaldehyde was calibrated five times and the cyclohexanes twice. The results of all the calibrations from UBWOS2013 for the PTR-QMS are shown in Fig. 2a and b. Clear differences in the gas calibration standard tanks for some compounds were observed. We have used historical calibration data to determine which of the tanks is likely to be the most accurate for each compound, and used those values in the final data analysis. Nevertheless, we define the instrument accuracy as the difference in the calibration tanks of better than $20 \%$. The quadrupole is a mass filter and measures only one mass at a time. During the measurements presented here the PTR-QMS was set to measure 34 masses related to VOCs with a $1 \mathrm{~s}$ dwell time every $37 \mathrm{~s}$. A common 1 min data format was used for all instruments during UBWOS2013 and therefore either one or two $1 \mathrm{~s}$ dwell time measurements were used for the $1 \mathrm{~min}$ data.

The PTR-TOF (owned by the University of Wyoming) is a commercial instrument that was acquired from Ionicon Analytik about 1 month before the field experiment. The operating conditions were $2.2 \mathrm{mbar}$ and $600 \mathrm{~V}$ resulting in an $E / N$ of about $130 \mathrm{Td}$ in the drift tube. Instrument backgrounds were determined similar to the PTR-QMS every $3 \mathrm{~h}$ for 1.5 min using a similar catalytic converter. Calibrations were done less frequently, but the same gas standards and MOCCS system were used. The calibration results from UBWOS2013 for the PTR-TOF are shown in Fig. 2c. Only three calibrations are available and the average sensitivity value was used for the entire campaign. As will be described below, the primary ion signal in the PTR-TOF was slightly unstable over the course of the campaign, but we still estimate the accuracy to be within $20 \%$. In the PTR-TOF, mass spectra from 1 to $500 \mathrm{amu}$ with an extraction frequency of $25 \mathrm{kHz}$ were pre-averaged and recorded as $10 \mathrm{~s}$ spectra, which were then further averaged to the $1 \mathrm{~min}$ UBWOS standard data format. The measured signal on $m / z 21$ was used to normalize to changing primary ions. A HPTDC (high-performance time-to-digital converter) was used for the TOF data acquisition. It has eight channels with $25 \mathrm{ps}$ time bin width. The PTR-TOF is not run at a faster time resolution than $100 \mathrm{ps}$ bin with. The number of fast channels is seven plus one trigger channel. The dead time is $10-20 \mathrm{~ns}$ and the event size is 4 bytes.

\section{Intercomparison}

\subsection{Sensitivity}

The sensitivity determined during the calibration measurements of the PTR-QMS and the PTR-TOF is compared in Fig. 3. The standard way of expressing the PTR-QMS sensitivity is in units of ncps (normalized counts per second) $\mathrm{ppbv}^{-1}$ (de Gouw and Warneke, 2007), which normalizes the calibration signal to $10^{6} \mathrm{H}_{3} \mathrm{O}^{+}$primary ions.

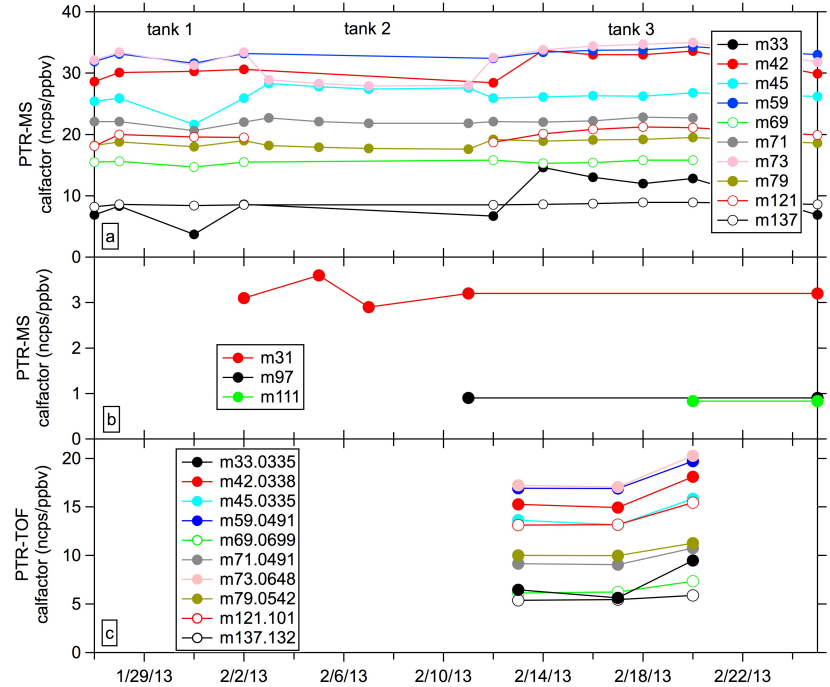

Figure 2. (a) Multiple VOC PTR-QMS calibration using three different calibration gas tanks during UBWOS2013: methanol (m33), acetonitrile ( $\mathrm{m} 42)$, acetaldehyde ( $\mathrm{m} 45)$, acetone (m59) isoprene (m69), methacrolein (m71), methylethylketone (m73), benzene (m79), 1,3,5-trimethylbenzene (m121) and $\alpha$-pinene (m137). (b) PTR-QMS calibrations using the MOCCS cart for formaldehyde (m31), methylcyclohexane (m97) and dimethylcyclohexane (m111). (c) PTR-TOF calibration for the same compounds as in (a) during UBWOS2013.

Figure 3a shows that the PTR-QMS and PTR-TOF have very comparable normalized sensitivities for the individual compounds, as can be expected, because similar drift tube reaction chambers are used. The PTR-QMS sensitivity in ncps ppbv ${ }^{-1}$ is higher, because the PTR-QMS drift tube is $1 \mathrm{~cm}$ longer and 2.4 mbar are used in the drift tube at similar $E$ / $N$ compared to the PTR-TOF. Also, the transmission efficiency for $\mathrm{H}_{3} \mathrm{O}^{+}$in the PTR-QMS is smaller compared to the product ions. The PTR-TOF data were analyzed with the software package described by Müller et al. (2013) and are corrected for dead time, baseline and most notably mass discrimination. The mass discrimination is caused by the sampling duty cycle in the orthogonal-acceleration region of the TOF. The duty cycle is mass dependent because different mass ions coming from the drift tube have a different velocity in the orthogonal accelerator. The smaller masses are faster and a larger fraction reaches the end of the orthogonal accelerator and is therefore lost there. The resulting mass discrimination is $\left[(\mathrm{m} / \mathrm{z})_{\max } /(\mathrm{m} / \mathrm{z})\right]^{0.5}$. The normalization to the primary ions for both instruments and the mass discrimination are removed in Fig. $3 b$ to compare sensitivities in actual count rates. The primary ion signal for the PTR-TOF used in Fig. $3 \mathrm{~b}$ was $1.6 \times 10^{6}$ ions and for the PTR-QMS $25 \times 10^{6}$ ions, about a factor of 15 higher (see discussion of Fig. 6a). On average, the PTR-QMS is about a factor of 20 more sensitive than the PTR-TOF in cps ppbv ${ }^{-1}$. The difference in sensitivity is dependent on the mass be- 

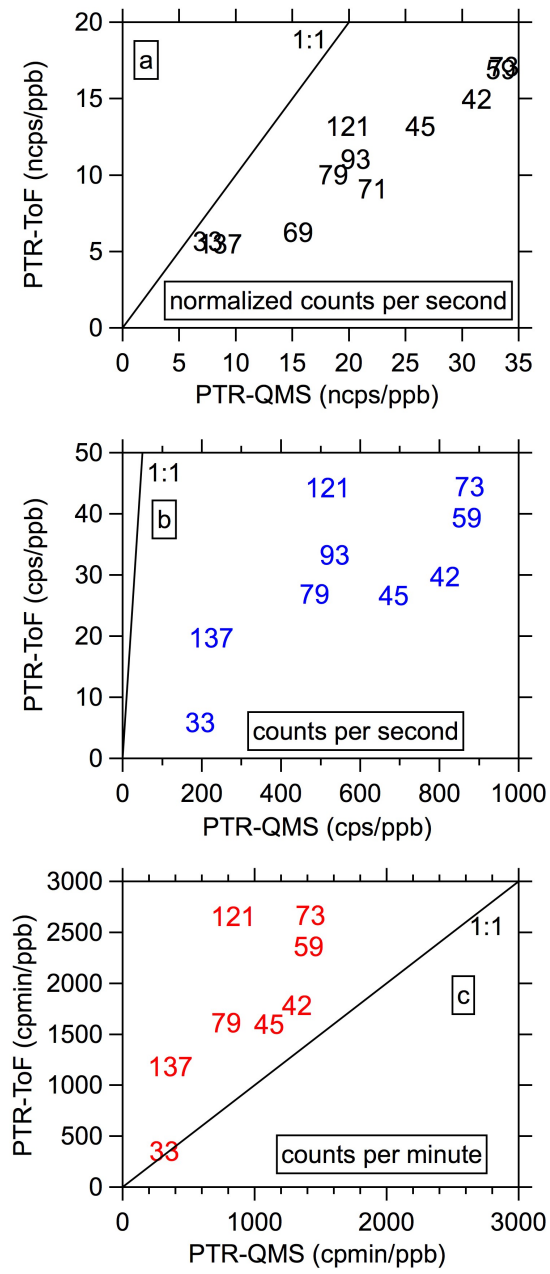

Figure 3. (a) PTR-QMS and PTR-TOF sensitivity in ncps ppbv ${ }^{-1}$ normalized to $1 \times 10^{6} \mathrm{H}_{3} \mathrm{O}^{+}$ions. (b) Sensitivity in cps ppbv ${ }^{-1}$ with PTR-QMS $25 \times 10^{6}$ and PTR-TOF $1.6 \times 10^{6} \mathrm{H}_{3} \mathrm{O}^{+}$ions. (c) Sensitivity in cpmin $\mathrm{ppbv}^{-1}$ with PTR-QMS measuring 37 ions. The numbers in (a), (b) and (c) are the nominal mass of the calibrated compounds.

cause of the mass discrimination of the PTR-TOF (Müller et al., 2013) and the transmission efficiency of the PTR-QMS (de Gouw and Warneke, 2007). The sensitivity here is expressed as cps ppbv ${ }^{-1}$, but the PTR-QMS measures only one mass per second, while the PTR-TOF takes full mass spectra, which compensates for the lower sensitivity, if multiple masses are measured with the PTR-QMS. During UBWOS2013, the PTR-QMS measured 34 masses in 37 s duty cycles and the final data protocol required the use of $1 \mathrm{~min}$ data. In Fig. $3 c$ the sensitivities from both instruments are compared in counts per minute per ppbv (cpmin ppbv ${ }^{-1}$ ) and in this comparison the PTR-TOF is now the more sensitive instrument.

The ratio of the sensitivities taken from Fig. $3 \mathrm{~b}$ of PTRQMS / PTR-TOF is plotted in Fig. 4a and is closely related
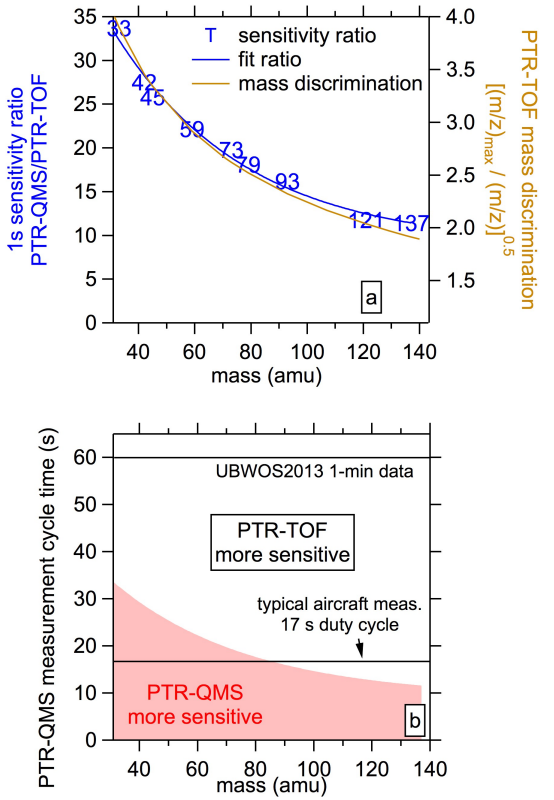

Figure 4. (a) The ratio of the $1 \mathrm{~s}$ sensitivities of PTR-QMS / PTRTOF together with the PTR-TOF mass discrimination. (b) A massdependent curve showing the length of the PTR-QMS measurement cycle, where the PTR-QMS is as sensitive as the PTR-TOF (identical to the fit in a). In aircraft measurements a duty cycle of $17 \mathrm{~s}$ is typical (PTR-TOF more sensitive above mass 80) and at ground sites 1 min measurements are typical (PTR-TOF more sensitive for all masses).

to the mass discrimination of the PTR-TOF, which is also shown in Fig. 4a. This also shows that the mass discrimination of the PTR-QMS is small in comparison and the remaining mass-dependent discrimination for both instruments is very similar. This ratio then determines at what length of the PTR-QMS duty cycle, assuming $1 \mathrm{~s}$ dwell time per mass, the PTR-TOF becomes more sensitive, which is shown in Fig. 4b. For UBWOS2013, 1 min measurements are reported, in which case the PTR-TOF is more sensitive for all masses. During aircraft measurements such as those done during CalNex2010 (Warneke et al., 2011b), a duty cycle of about $17 \mathrm{~s}$ was used, in which case the PTR-QMS would be more sensitive for masses below $80 \mathrm{amu}$ and the PTR-TOF above 80 amu.

\subsection{Noise and detection limits}

The detection limit of the instruments depends not only on the sensitivity, but also on the signal noise and the instrument background. Due to the Poisson distribution of the signal, the noise is the square root of the signal for all the product ions (if the gain on the multichannel plates (MCP) is set high enough). Primary ion signals are so large that undercounting has an influence on the noise and signal detection. This has been previously demonstrated for PTR-QMS and for in- 


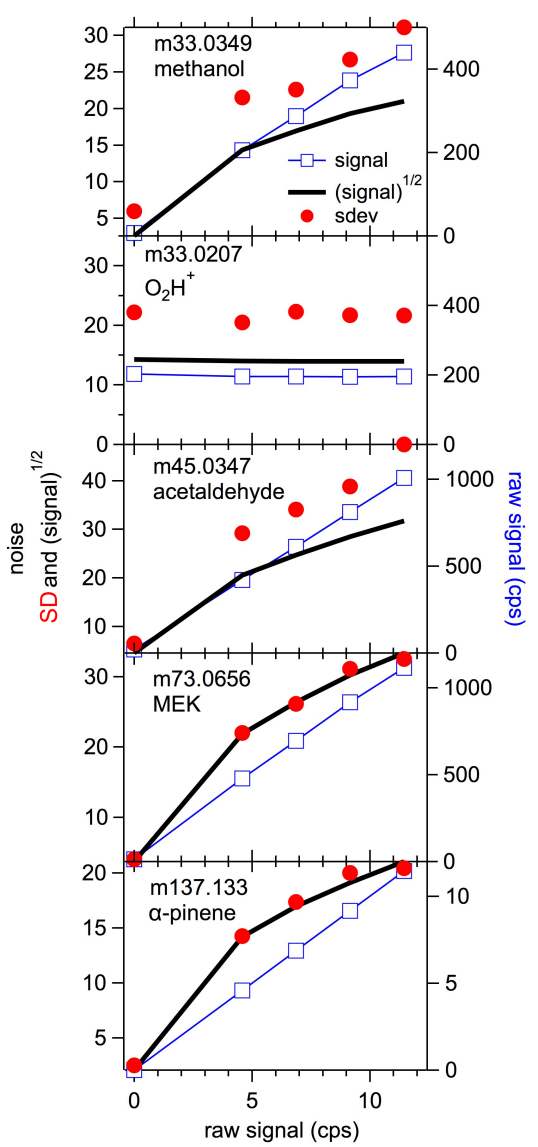

Figure 5. Signal, (signal) $)^{1 / 2}$, and standard deviation (SD) of the signal (noise) during a typical PTR-TOF calibration measurement for some selected masses.

struments that are operated in ion counting mode due to the dead time of the electron multiplier (de Gouw and Warneke, 2007). For a typical PTR-TOF calibration measurement, the signal, the measured noise and the square root of the signal for some selected masses are shown in Fig. 5. For most masses the noise is basically identical to the square root of the signal as can be seen in Fig. 5 for mass 73.0656 (methyl ethyl ketone) and mass 137.133 ( $\alpha$-pinene). There are some exceptions, which are shown by mass 33.0349 (methanol), mass $33.0207\left(\mathrm{O}_{2} \mathrm{H}^{+}\right)$and mass 45.0347 (acetaldehyde). The baseline is increased near peaks with very large signals, such as the primary ions $\left(\mathrm{H}_{3} \mathrm{O}^{+}, \mathrm{O}_{2}^{+}\right.$, etc.), increasing the noise on masses close to these peaks. The baseline increase can be seen in a mass spectrum in Fig. 9a.

The detection limit is calculated from the sensitivity and the noise on the background signals determined using the catalytic converter measurements. The detection limits are 3 times $(\mathrm{S} / \mathrm{N}=3)$ the standard deviation of the background measurements, where $30 \mathrm{~s}$ averaging times for the PTR-TOF and the $37 \mathrm{~s}$ measurements for the PTR-QMS were used. The results are shown for a few selected compounds in Fig. 6 .

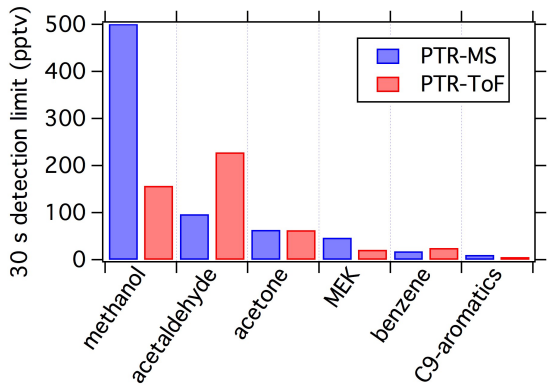

Figure 6. PTR-QMS and PTR-TOF $30 \mathrm{~s}$ detection limits during UBWOS2013.

The detection limits are comparable for both instruments but improve with increasing mass for the PTR-TOF, as is expected due to the increase in sensitivity with mass. Two notable exceptions in Fig. 6 are methanol and acetaldehyde. In the PTR-QMS the instrument background is comprised of mainly $\mathrm{O}_{2} \mathrm{H}^{+}$and methanol $\cdot \mathrm{H}^{+}$ions, which can be separated by mass in the PTR-TOF (Li et al., 2014). As a result, the PTR-TOF has a much smaller instrument background than the PTR-QMS and therefore also a lower detection limit. This effect can be observed for all compounds, where the background signal is comprised of more than one isobaric ion as for example acetonitrile (Dunne et al., 2012). The instrument background and therefore also the detection limit of the PTR-TOF for acetaldehyde was elevated during UBWOS2013, likely because the instrument was new and not run long enough for the background levels to drop.

\subsection{Mixing ratios}

PTR-TOF and PTR-QMS have recently been successfully compared (Kaser et al., 2013; Park et al., 2013). In Fig. 7 the intercomparison for acetone for UBWOS2013 is shown. In the top panel the time series for acetone on mass 59 from the PTR-QMS and on mass 59.0491 from the PTR-TOF are shown together with the respective primary ion signals. Over the whole time period the acetone measurements agree very well with a slope of 1.03 and an $R^{2}$ of 0.982 .

The PTR-QMS was very stable, whereas the PTR-TOF primary ion signal was variable during the campaign. The PTR-TOF instrument was new and only briefly tested in the laboratory before being deployed during the field experiment. Therefore, various issues with the setup and the software had to be resolved during the field deployment, resulting in the large changes in primary ion signals and therefore sensitivity and detection limits. Most issues were the result of software instability, but the TOF, the MCP, and the ion source also had to be retuned during the experiment. For the measurements of the detection limit as described above, a period was chosen, where the primary ion signal was around $1.6 \times 10^{6} \mathrm{cps}$. At high MCP gain voltages, continuous operation and high signal intensities the detector may deterio- 


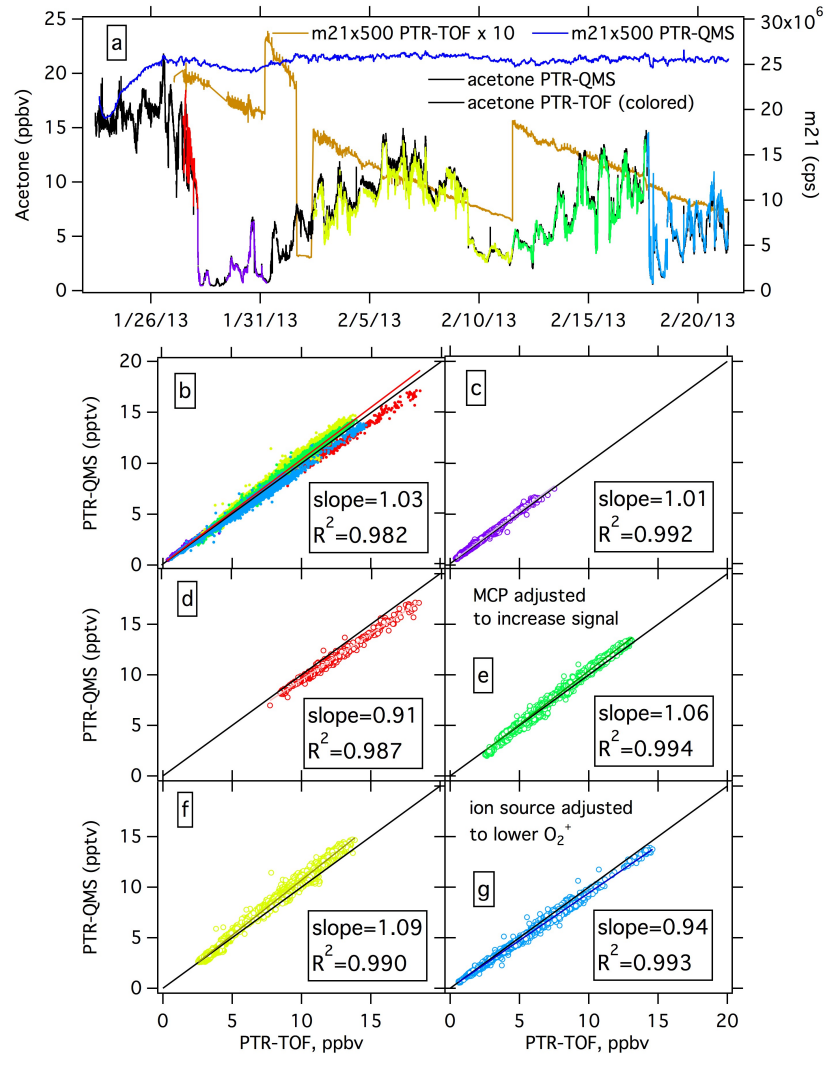

Figure 7. PTR-QMS and PTR-TOF acetone intercomparison during UBWOS2013: (a) time series of the PTR-TOF and PTR-QMS primary ions and acetone. The color code of the PTR-TOF acetone signal indicates when the PTR-TOF was relatively stable. (b) Scatter plot of PTR-QMS and PTR-TOF acetone for the whole campaign. (c-g) Scatter plots for separate stable periods of the PTRTOF.

rate relatively quickly. Excessively high gain voltages may cause a more rapid deterioration, and a more frequent readjustment of the MCP gain in small steps should - all other things being equal - lead to a more constant signal. The detector deterioration due to high gain operation is a necessary trade-off to avoid an additional mass discrimination introduced by the MCP (Müller et al., 2014). Other reasons for the changes in sensitivity after software crashes and other instrument failures include the raw baseline stability, because the HPTDC was not temperature controlled, and changes in the statically set threshold levels and mass-dependent single ion peak detection at varying MCP gain voltages. All these features of the TOF operation were not monitored throughout the campaign; instead, the sensitivity of the instrument was monitored with calibrations using a calibration standard with compounds covering the mass range of interest.

The lower panels in Fig. 7 show the intercomparison separated into periods, when the PTR-TOF was relatively stable in a specific mode (except for the deterioration of the signal due to the MCP). For each individual period the comparison
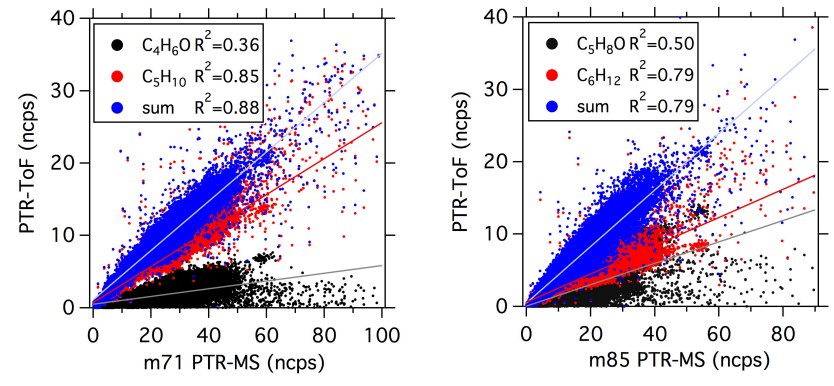

Figure 8. PTR-QMS and PTR-TOF intercomparison for mass 71 and mass 85 during UBWOS2013.

is excellent with $R^{2} \geq 0.987$ and the slope varies between $\pm 9 \%$ of unity. For the PTR-TOF only three calibrations are available and the averages from the three calibrations were used for the whole time period. This shows that without frequent calibrations an additional error of $\pm 10 \%$ can be expected if the instrument setup is not stable during the experiment.

Many other masses routinely measured by PTR-QMS, where generally only one VOC contributes to the signal (methanol, acetaldehyde, benzene, toluene and many others), agreed well within the stated uncertainties with the PTRTOF: $R^{2} \geq 0.92$ and $\pm 20 \%$. Benzene from the PTR-TOF and PTR-QMS agreed within $3 \%$ and $R^{2}=0.98$. The PTRTOF measurements of benzene were also compared with a GC-FID (gas chromatography-flame ionization detector) system; the PTR-TOF agreed with an $R^{2}=0.96$ but its results were larger by $22 \%$. This difference is within the stated uncertainties, but larger than observed in previous intercomparisons (Warneke et al., 2011a). Figure 8 shows the comparison of masses 71 and 85 in ncps as examples. The PTRTOF detects two separate peaks on each of those nominal masses and identifies their atomic compositions as $\mathrm{m} 71.0491$ $\left(\mathrm{C}_{4} \mathrm{H}_{6} \mathrm{O} \cdot \mathrm{H}^{+}\right)$and $\mathrm{m} 71.083\left(\mathrm{C}_{5} \mathrm{H}_{10} \cdot \mathrm{H}^{+}\right)$, and $\mathrm{m} 85.0647$ $\left(\mathrm{C}_{5} \mathrm{H}_{8} \mathrm{O} \cdot \mathrm{H}^{+}\right)$and $\mathrm{m} 85.0966\left(\mathrm{C}_{6} \mathrm{H}_{12} \cdot \mathrm{H}^{+}\right)$. The PTR-QMS correlates the best with the sum of the two compounds for both masses as expected. The sensitivity of the PTR-QMS in ncps ppb ${ }^{-1}$ is close to a factor of 2 larger than the PTR-TOF (Fig. 3a), which is reflected in the slope in Fig. 8 as well. Other compounds that were compared are $\mathrm{H}_{2} \mathrm{~S}$, which is discussed elsewhere (Li et al., 2014), and formaldehyde. Both of those compounds have only a slightly higher proton affinity than water and have therefore much lower sensitivities and need to be calibrated frequently (Warneke et al., 2011b). Formaldehyde calibrations for the PTR-TOF are not available, but the comparison of the signals in ncps showed an $R^{2}=0.88$. 

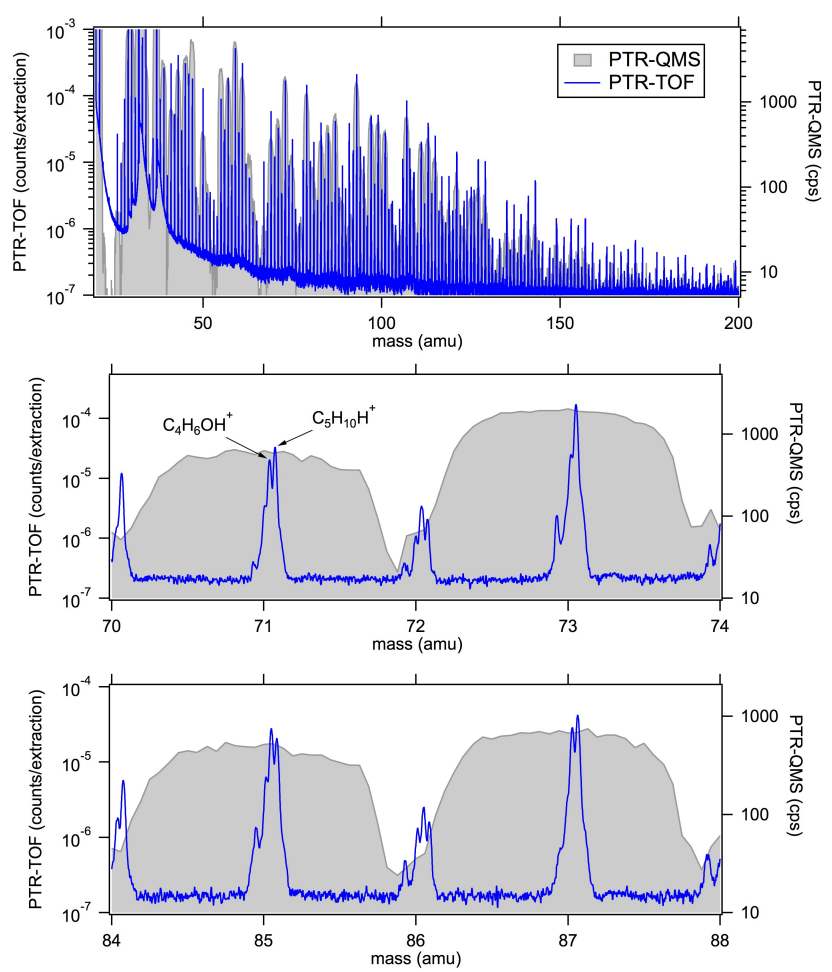

Figure 9. PTR-QMS and PTR-TOF mass scans. As an example, for $m / z 71$ two isobars are identified with the PTR-TOF and labeled.

\section{Mass resolution and additional science possible with PTR-TOF}

One of the two main differences between PTR-QMS and PTR-TOF is the achievable mass resolution: unity for the PTR-QMS and 4000-5000 for the PTR-TOF (Graus et al., 2010). Figure 9 shows mass spectra from both instruments for the full range and four selected masses. The PTR-QMS mass spectrum is an average of three cycles, where each mass $(m / z 20-200)$ was measured for $1 \mathrm{~s}$ each resulting in a total of 9 min measurements. The PTR-TOF spectrum is an average of all spectra over those 9 min. Figure 9 shows that at one nominal mass, as measured by the PTR-QMS, up to four nominally isobaric ions are seen in the PTR-TOF. As an example two isobaric ions are identified with the PTR-TOF in Fig. 9 for $m / z 71: \mathrm{C}_{4} \mathrm{H}_{6} \mathrm{OH}^{+}$and $\mathrm{C}_{5} \mathrm{H}_{10} \mathrm{H}^{+}$.

Isomeric ions have the same molecular formula and the exact same mass, whereas isobaric ions have the same nominal mass, but have a different molecular formula and a different exact mass. Therefore, the PTR-TOF can only distinguish between isobaric ions and nonisomeric ions.

The composition of each nominal mass, where the PTRTOF detected signal in ambient air, is shown in Fig. 10. In the Uintah Basin large emissions of alkanes, cycloalkanes and aromatics from the oil and gas industry result in a rather unusual VOC composition and as a result many of the observed mass peaks are hydrocarbons. Subsequent photochemical

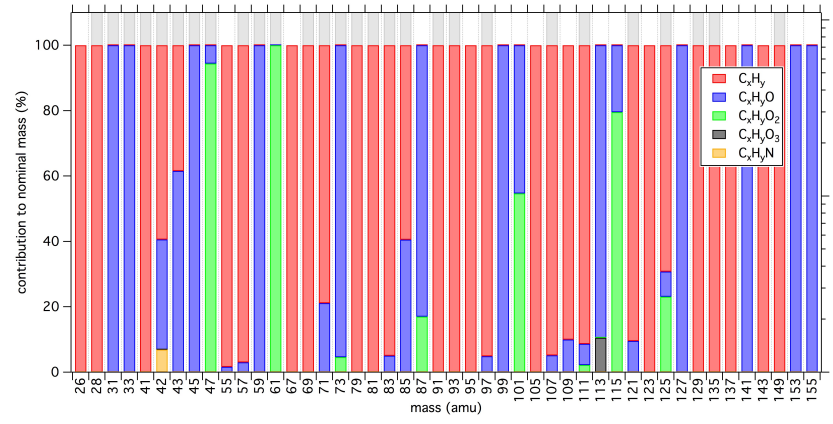

Figure 10. PTR-TOF mass contributions for all the masses that showed ambient signal during UBWOS2013. The grey bars on top indicate the masses that were monitored with the PTR-QMS.

oxidation of the alkanes produced many oxygenated compounds and VOCs with up to three oxygen atoms. In Fig. 10 the grey shaded masses are the ones that were monitored with the PTR-QMS and it can be seen that for most compounds either the hydrocarbon $\mathrm{C}_{\mathrm{x}} \mathrm{H}_{\mathrm{y}}$ or the $\mathrm{C}_{\mathrm{x}} \mathrm{H}_{\mathrm{y}} \mathrm{O}$ structure dominates the signal on that nominal mass. This means that in principle with PTR-QMS the same information is obtained for the dominant peak on that mass, but the molecular identity is still not known and has to be assumed from prior knowledge of the emissions or chemistry. But in many cases multiple isobaric ions contribute to the signal at a nominal mass and the PTR-TOF provides identification of VOCs that are not separable with PTR-QMS.

The photo-oxidation products of some alkanes, cycloalkanes and aromatics, which are detectable with $\mathrm{H}_{3} \mathrm{O}^{+}$ions, but have interferences on the PTR-QMS, can be quantified by PTR-TOF. The diurnal profiles for the UBWOS2013 campaign of many of those compounds are shown in Fig. 11. It can be seen that similar homologues of VOCs such as the acids, ketones or cycloketones have very similar diurnal profiles, but they are different from another. Often the signals corresponding to these compounds, especially $\mathrm{C}_{\mathrm{x}} \mathrm{H}_{\mathrm{y}} \mathrm{O}_{2}$ structures, are very small and have the same nominal mass as $\mathrm{C}_{\mathrm{x}} \mathrm{H}_{\mathrm{y}} \mathrm{O}$ compounds. For example, mass 73 is mainly comprised of methyl ethyl ketone $\left(\mathrm{C}_{4} \mathrm{H}_{9} \mathrm{O}\right)$ and has a small contribution of methylglyoxal $\left(\mathrm{C}_{3} \mathrm{H}_{5} \mathrm{O}_{2}\right)$. Methylglyoxal is a very important compound in the chemistry leading to wintertime ozone exceedances in the Uintah Basin, because it acts as a radical precursor (Edwards et al., 2013). The detection of methylglyoxal is not possible with PTR-QMS, but feasible with PTR-TOF and has added greatly to our understanding of wintertime ozone formation.

\section{Conclusions}

PTR-TOF has been a significant step in the evolution and improvement of the PTR technique to monitor VOCs in the atmosphere, where the main advantages of the TOF are the 


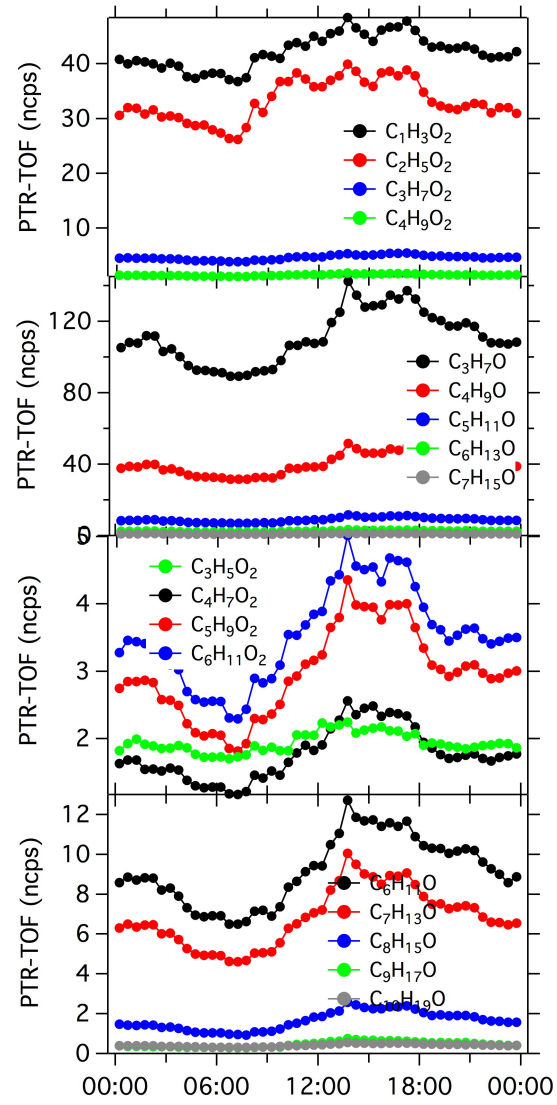

Figure 11. PTR-TOF diurnal variation of selected oxygenated VOCs during UBWOS2013. Many of those compounds cannot be unambiguously identified with PTR-QMS.

high time resolution for full mass scans and the high mass resolution of 4000-5000 compared to the unit mass resolution with PTR-QMS. The high mass resolution allows for the identification of isobaric ions. Here we compared a standard PTR-QMS with a new PTR-TOF during the UBWOS2013 field experiment in an oil and gas field in the Uintah Basin, Utah.

The setup of the measurements with the two instruments determines which instrument is more sensitive. The difference in sensitivity is dependent on the mass: the PTR-TOF is increasingly more sensitive with increasing mass, and at above $80 \mathrm{amu}$ it becomes more sensitive than the PTR-QMS. In PTR-QMS, the masses that are monitored need to be chosen. If only one mass is measured with $1 \mathrm{~s}$ dwell time, the PTR-QMS is about a factor of 10-35 more sensitive depending on the mass. The number of masses monitored in PTRQMS and the averaging times then determine which instrument is more sensitive: 10-35 masses for $1 \mathrm{~s}$ dwell times, again dependent on the mass, is the break-even point. During UBWOS2013 the PTR-QMS was set to monitor 34 masses in $37 \mathrm{~s}$ and data for both instruments were reported as $1 \mathrm{~min}$ averages. In this setup the PTR-TOF is more sensitive for all masses.

The high mass resolution of the PTR-TOF showed that many masses monitored with the PTR-QMS had contributions from only one ion, but that many others had contributions from up to four different isobaric ions. This capability gives the PTR-TOF the ability to measure small oxidation products of the main emissions from the oil and gas development (alkanes, cycloalkanes and aromatics) that play an important role in the formation of ozone. These compounds were previously not individually measurable by PTR-QMS.

Overall, the two instruments agreed for measured mixing ratios very well for all compounds where calibration gases were available and for measured count rates for all other compounds $\left(R^{2} \geq 0.92\right.$ and within $\left.20 \%\right)$. For masses, where more than one isobaric ion contributes to the signal, the PTRQMS agreed with the sum of those ions observed with the PTR-TOF.

The additional analytical capabilities and the sensitivity of the current PTR-TOF version are clearly a major advance in PTR technology for VOC analysis compared to the standard PTR-QMS instruments. For measurements aboard aircraft, where PTR-QMS instruments excel by commonly monitoring only a few selected ions and thus achieve high sensitivities, PTR-TOF instruments could still be improved in sensitivity to achieve the same detection limits as PTR-QMS instruments. A promising new development for a sensitivity improvement of PTR-TOF has recently been shown by Sulzer et al. (2014), which could make PTR-TOF the ideal instrument for aircraft measurements as well.

Acknowledgements. We thank Questar Energy Products, in particular Stephanie Tomkinson, for the Horse Pool site preparation and logistical support. This work was supported in part by the Western Energy Alliance. This work was also supported by the NOAA Health of the Atmosphere Program and by the NOAA Climate Program Office - Atmospheric Composition and Climate Program. Shane Murphy was supported by the NSF grant 1215926. S.-M. Li was supported in part by Environment Canada's Clean Air Regulatory Agenda.

Edited by: E. C. Apel

\section{References}

Blake, R. S., Whyte, C., Hughes, C. O., Ellis, A. M., and Monks, P. S.: Demonstration of proton-transfer reaction time-of-flight mass spectrometry for real-time analysis of trace volatile organic compounds, Anal. Chem., 76, 3841-3845, 2004.

Blake, R. S., Monks, P. S., and Ellis, A. M.: Proton-Transfer Reaction Mass Spectrometry, Chem. Rev., 109, 861-896, 2009.

de Gouw, J. A. and Warneke, C.: Measurements of volatile organic compounds in the earths atmosphere using proton-transferreaction mass spectrometry, Mass Spectrom. Rev., 26, 223-257, 2007. 
de Gouw, J. A., Goldan, P. D., Warneke, C., Kuster, W. C., Roberts, J. M., Marchewka, M., Bertman, S. B., Pszenny, A. A. P., and Keene, W. C.: Validation of proton transfer reaction-mass spectrometry (PTR-MS) measurements of gas-phase organic compounds in the atmosphere during the New England Air Quality Study (NEAQS) in 2002, J. Geophys. Res.-Atmos., 108, 4682, doi:10.1029/2003JD003863, 2003.

Dunne, E., Galbally, I. E., Lawson, S., and Patti, A.: Interference in the PTR-MS measurement of acetonitrile at $m / z 42$ in polluted urban air-A study using switchable reagent ion PTR-MS, Int. J. Mass Spectrom., 319, 40-47, 2012.

Edwards, P. M., Young, C. J., Aikin, K., deGouw, J., Dubé, W. P., Geiger, F., Gilman, J., Helmig, D., Holloway, J. S., Kercher, J., Lerner, B., Martin, R., McLaren, R., Parrish, D. D., Peischl, J., Roberts, J. M., Ryerson, T. B., Thornton, J., Warneke, C., Williams, E. J., and Brown, S. S.: Ozone photochemistry in an oil and natural gas extraction region during winter: simulations of a snow-free season in the Uintah Basin, Utah, Atmos. Chem. Phys., 13, 8955-8971, doi:10.5194/acp-13-8955-2013, 2013.

Gilman, J. B., Lerner, B. M., Kuster, W. C., and de Gouw, J. A.: Source Signature of Volatile Organic Compounds from Oil and Natural Gas Operations in Northeastern Colorado, Environ. Sci. Technol., 47, 1297-1305, 2013.

Graus, M., Mueller, M., and Hansel, A.: High Resolution PTRTOF: Quantification and Formula Confirmation of VOC in Real Time, J. Am. Soc. Mass Spectr., 21, 1037-1044, 2010.

Haase, K. B., Keene, W. C., Pszenny, A. A. P., Mayne, H. R., Talbot, R. W., and Sive, B. C.: Calibration and intercomparison of acetic acid measurements using proton-transfer-reaction mass spectrometry (PTR-MS), Atmos. Meas. Tech., 5, 27392750, doi:10.5194/amt-5-2739-2012, 2012.

Hansel, A., Jordon, A., Holzinger, R., Prazeller, P., Vogel, W., and Lindinger, W.: Proton transfer reaction mass spectrometry: Online trace gas analysis at the ppb level, Int. J. Mass Spectrom., 149/150, 609-619, 1995.

Hansel, A., Jordan, A., Warneke, C., Holzinger, R., Wisthaler, A., and Lindinger, W.: Proton-transfer-reaction mass spectrometry (PTR-MS): on-line monitoring of volatile organic compounds at volume mixing ratios of a few pptv, Plasma Sources Sci. T., 8, 332-336, 1999.

Helmig, D., Thompson, C. R., Evans, J., Boylan, P., Hueber, J., and Park, J. H.: Highly Elevated Atmospheric Levels of Volatile Organic Compounds in the Uintah Basin, Utah, Environ. Sci. Technol., 48, 4707-4715, doi:10.1021/es405046r, 2014.

Howarth, R. W., Santoro, R., and Ingraffea, A.: Methane and the greenhouse-gas footprint of natural gas from shale formations, Climatic Change, 106, 679-690, 2011.

Jordan, A., Haidacher, S., Hanel, G., Hartungen, E., Maerk, L., Seehauser, H., Schottkowsky, R., Sulzer, P., and Maerk, T. D.: A high resolution and high sensitivity proton-transfer-reaction time-of-flight mass spectrometer (PTR-TOF-MS), Int. J. Mass Spectrom., 286, 122-128, 2009.

Karion, A., Sweeney, C., Petron, G., Frost, G., Hardesty, R. M., and Kofler, J.: Methane emissions estimate from airborne measurements over a western United States natural gas field, Geophys. Res. Lett., 40, 4393-4397, doi:10.1002/grl.50811, 2013.

Karl, T., Guenther, A. B., Lindinger, C., Jordan, A., Fall, R., and Lindinger, W.: Eddy covariance measurements of oxygenated volatile organic compound fluxes from crop harvesting us- ing a redesigned proton-transfer-reaction mass spectrometer, J. Geophys. Res., 106, 24157-24167, doi:10.1029/2000JD000112, 2001.

Kaser, L., Karl, T., Schnitzhofer, R., Graus, M., Herdlinger-Blatt, I. S., DiGangi, J. P., Sive, B., Turnipseed, A., Hornbrook, R. S., Zheng, W., Flocke, F. M., Guenther, A., Keutsch, F. N., Apel, E., and Hansel, A.: Comparison of different real time VOC measurement techniques in a ponderosa pine forest, Atmos. Chem. Phys., 13, 2893-2906, doi:10.5194/acp-13-2893-2013, 2013.

Katzenstein, A. S., Doezema, L. A., Simpson, I. J., Blake, D. R., and Rowland, F. S.: Extensive regional atmospheric hydrocarbon pollution in the southwestern United States, P. Natl. Acad. Sci. USA, 100, 11975-11979, 2003.

Kemball-Cook, S., Bar-Ilan, A., Grant, J., Parker, L., Jung, J. G., Santamaria, W., Mathews, J., and Yarwood, G.: Ozone Impacts of Natural Gas Development in the Haynesville Shale, Environ. Sci. Technol., 44, 9357-9363, 2010.

Li, R., Warneke, C., Graus, M., Field, R., Geiger, F., Veres, P. R., Soltis, J., Li, S.-M., Murphy, S. M., Sweeney, C., Pétron, G., Roberts, J. M., and de Gouw, J.: Measurements of hydrogen sulfide (H2S) using PTR-MS: calibration, humidity dependence, inter-comparison and results from field studies in an oil and gas production region, Atmos. Meas. Tech., 7, 3597-3610, doi:10.5194/amt-7-3597-2014, 2014

Lindinger, W., Hansel, A., and Jordan, A.: On-line monitoring of volatile organic compounds at pptv levels by means of protontransfer-reaction mass spectrometry (PTR-MS) - Medical applications, food control and environmental research, Int. J. Mass Spectrom., 173, 191-241, doi:10.1016/0168-1176(97)00281-4, 1998a.

Lindinger, W., Hansel, A., and Jordan, A.: Proton-transfer-reaction mass spectrometry (PTR-MS): on-line monitoring of volatile organic compounds at pptv levels, Chem. Soc. Rev., 27, 347-354, doi:10.1039/a827347z, 1998b.

Litovitz, A., Curtright, A., Abramzon, S., Burger, N., and Samaras, C.: Estimation of regional air-quality damages from Marcellus Shale natural gas extraction in Pennsylvania, Environ. Res. Lett., 8, 014017, doi:10.1088/1748-9326/8/1/014017, 2013.

Mielke, L. H., Erickson, D. E., McLuckey, S. A., Mueller, M., Wisthaler, A., Hansel, A., and Shepson, P. B.: Development of a Proton-Transfer Reaction-Linear Ion Trap Mass Spectrometer for Quantitative Determination of Volatile Organic Compounds, Anal. Chem., 80, 8171-8177, 2008.

Müller, M., Mielke, L. H., Breitenlechner, M., McLuckey, S. A., Shepson, P. B., Wisthaler, A., and Hansel, A.: MS/MS studies for the selective detection of isomeric biogenic VOCs using a Townsend Discharge Triple Quadrupole Tandem MS and a PTR-Linear Ion Trap MS, Atmos. Meas. Tech., 2, 703-712, doi:10.5194/amt-2-703-2009, 2009.

Müller, M., Graus, M., Ruuskanen, T. M., Schnitzhofer, R., Bamberger, I., Kaser, L., Titzmann, T., Hörtnagl, L., Wohlfahrt, G., Karl, T., and Hansel, A.: First eddy covariance flux measurements by PTR-TOF, Atmos. Meas. Tech., 3, 387-395, doi:10.5194/amt-3-387-2010, 2010.

Müller, M., Mikoviny, T., Jud, W., D’Anna, B., and Wisthaler, A.: A new software tool for the analysis of high resolution PTR-TOF mass spectra, Chemometr. Intell. Lab., 127, 158-165, 2013.

Müller, M., Mikoviny, T., and Wisthaler, A.: Detector aging induced mass discrimination and non-linearity effects 
in PTR-ToF-MS, Int. J. Mass Spectrom., 365-366, 93-97, doi:10.1016/j.ijms.2013.12.008, 2014.

Park, J.-H., Goldstein, A. H., Timkovsky, J., Fares, S., Weber, R., Karlik, J., and Holzinger, R.: Eddy covariance emission and deposition flux measurements using proton transfer reaction - time of flight - mass spectrometry (PTR-TOF-MS): comparison with PTR-MS measured vertical gradients and fluxes, Atmos. Chem. Phys., 13, 1439-1456, doi:10.5194/acp-13-1439-2013, 2013.

Petron, G., Frost, G., Miller, B. R., Hirsch, A. I., Montzka, S. A., Karion, A., Trainer, M., Sweeney, C., Andrews, A. E., Miller, L., Kofler, J., Bar-Ilan, A., Dlugokencky, E. J., Patrick, L., Moore, C. T., Ryerson, T. B., Siso, C., Kolodzey, W., Lang, P. M., Conway, T., Novelli, P., Masarie, K., Hall, B., Guenther, D., Kitzis, D., Miller, J., Welsh, D., Wolfe, D., Neff, W., and Tans, P.: Hydrocarbon emissions characterization in the Colorado Front Range: A pilot study, J. Geophys. Res.-Atmos., 117, D04304, doi:10.1029/2011JD016360, 2012.

Prazeller, P., Palmer, P. T., Boscaini, E., Jobson, B. T., and Alexander, M.: Proton transfer reaction ion trap mass spectrometer, Rapid Commun. Mass Sp., 17, 1593-1599, 2003.

Schnell, R. C., Oltmans, S. J., Neely, R. R., Endres, M. S., Molenar, J. V., and White, A. B.: Rapid photochemical production of ozone at high concentrations in a rural site during winter, Nat. Geosci., 2, 120-122, 2009.

Sulzer, P., Edtbauer, A., Hartungen, E., Juerschik, S., Jordan, A., Hanel, G., Feil, S., Jaksch, S., Maerk, L., and Maerk, T. D.: From conventional proton-transfer-reaction mass spectrometry (PTRMS) to universal trace gas analysis, Int. J. Mass Spectrom., 321, 66-70, 2012.

Sulzer, P., Hartungen, E., Hanel, G., Feil, S., Winkler, K., Mutschlechner, P., Haidacher, S., Schottkowsky, R., Gunsch, D., Seehauser, H., Striednig, M., Jürschik, S., Breiev, K., Lanza, M., Herbig, J., Märk, L., Märk, T. D., and Jordan, A.: A Proton Transfer Reaction-Quadrupole interface TimeOf-Flight Mass Spectrometer (PTR-QiTOF): High speed due to extreme sensitivity, Int. J. Mass Spectrom., 368, 1-5, doi:10.1016/j.ijms.2014.05.004, 2014.

Tanimoto, H., Aoki, N., Inomata, S., Hirokawa, J., and Sadanaga, Y.: Development of a PTR-TOFMS instrument for real-time measurements of volatile organic compounds in air, Int. J. Mass Sp., 263, 1-11, 2007.

Veres, P., Gilman, J. B., Roberts, J. M., Kuster, W. C., Warneke, C., Burling, I. R., and de Gouw, J.: Development and validation of a portable gas phase standard generation and calibration system for volatile organic compounds, Atmos. Meas. Tech., 3, 683-691, doi:10.5194/amt-3-683-2010, 2010.

Warneke, C., van der Veen, C., Luxembourg, S., de Gouw, J. A., and Kok, A.: Measurements of benzene and toluene in ambient air using proton-transfer-reaction mass spectrometry: calibration, humidity dependence, and field intercomparison, Int. J. Mass Spectrom., 207, 167-182, 2001.
Warneke, C., De Gouw, J. A., Kuster, W. C., Goldan, P. D., and Fall, R.: Validation of atmospheric VOC measurements by proton-transfer-reaction mass spectrometry using a gaschromatographic preseparation method, Environ. Sci. Technol., 37, 2494-2501, 2003.

Warneke, C., Rosen, S., Lovejoy, E. R., de Gouw, J. A., and Fall, R.: Two additional advantages of proton-transfer ion trap mass spectrometry, Rapid Commun. Mass Sp., 18, 133-134, 2004.

Warneke, C., de Gouw, J. A., Lovejoy, E. R., Murphy, P. C., Kuster, W. C., and Fall, R.: Development of proton-transfer ion trap-mass spectrometry: On-line detection and identification of volatile organic compounds in air, J. Am. Soc. Mass Spectr., 16, 13161324, 2005a.

Warneke, C., Kato, S., De Gouw, J. A., Goldan, P. D., Kuster, W. C., Shao, M., Lovejoy, E. R., Fall, R., and Fehsenfeld, F. C.: Online volatile organic compound measurements using a newly developed proton-transfer ion-trap mass spectrometry instrument during New England Air Quality Study - Intercontinental Transport and Chemical Transformation 2004: Performance, intercomparison, and compound identification, Environ. Sci. Technol., 39, 5390-5397, 2005b.

Warneke, C., Roberts, J. M., Veres, P., Gilman, J., Kuster, W. C., Burling, I., Yokelson, R., and de Gouw, J. A.: VOC identification and inter-comparison from laboratory biomass burning using PTR-MS and PIT-MS, Int. J. Mass Spectrom., 303, 6-14, 2011a

Warneke, C., Veres, P., Holloway, J. S., Stutz, J., Tsai, C., Alvarez, S., Rappenglueck, B., Fehsenfeld, F. C., Graus, M., Gilman, J. B., and de Gouw, J. A.: Airborne formaldehyde measurements using PTR-MS: calibration, humidity dependence, intercomparison and initial results, Atmos. Meas. Tech., 4, 23452358, doi:10.5194/amt-4-2345-2011, 2011 b.

Warneke, C., Geiger, F., Edwards, P. M., Dube, W., Pétron, G., Kofler, J., Zahn, A., Brown, S. S., Graus, M., Gilman, J. B., Lerner, B. M., Peischl, J., Ryerson, T. B., de Gouw, J. A., and Roberts, J. M.: Volatile organic compound emissions from the oil and natural gas industry in the Uintah Basin, Utah: oil and gas well pad emissions compared to ambient air composition, Atmos. Chem. Phys., 14, 10977-10988, doi:10.5194/acp14-10977-2014, 2014.

Wisthaler, A., Apel, E. C., Bossmeyer, J., Hansel, A., Junkermann, W., Koppmann, R., Meier, R., Müller, K., Solomon, S. J., Steinbrecher, R., Tillmann, R., and Brauers, T.: Technical Note: Intercomparison of formaldehyde measurements at the atmosphere simulation chamber SAPHIR, Atmos. Chem. Phys., 8, 21892200, doi:10.5194/acp-8-2189-2008, 2008. 